\title{
EDITORIAL OPEN The efficacy and safety of inhaled corticosteroids: are we ignoring the potential advantages of ciclesonide?
}

npj Primary Care Respiratory Medicine (2014) 24, Article number: 14013; doi:10.1038/npjpcrm.2014.13; published online 20 May 2014

Inhaled corticosteroids (ICS) are still the cornerstone of treatment in asthma ${ }^{1}$ and many physicians also prescribe ICS in chronic obstructive pulmonary disease. ${ }^{2,3}$ The introduction of ICS in the late 1970 s caused a large shift in clinical practice regarding the treatment of asthma. Before that time asthma was considered a disease predominantly caused by proliferation of the smooth muscle cell and the only treatment for this was considered to be bronchodilators. When the efficacy of ICS was finally proven by several studies, ${ }^{4}$ and ICS were introduced in primary care, the number of deaths, hospital admissions and night-time calls for emergency primary care services almost disappeared. Furthermore, in many parts of the world ICS replaced the use of regular oral corticosteroids, and with that the incidence of severe side effects secondary to oral steroid treatment diminished.

Since then, asthma therapy guidelines have not changed much. The majority of asthma patients are still treated with a combination of ICS and short- or long-acting bronchodilators. Asthma guidelines recommend measuring asthma control and stepping-up of therapy when patients are uncontrolled on current therapy and stepping-down when patients are controlled. ${ }^{1}$ However, guidelines may be too conservative in that they ignore some evidence from both mechanistic and clinical studies regarding the development of inhaled steroids and their effects. ${ }^{1}$

The most important factor when deciding on ICS treatment is the balance between benefit and harm of the ICS concerned. Research over the past decades has shown that not all patients are equal. Although some patients might experience very few side effects from even high-dose ICS, research from Foster et al. ${ }^{5}$ showed that, when asked, most patients mentioned several side effects from their 'brown inhaler' such as hoarseness, thin skin and disturbed vision. Measurements of patient populations by Foster et $a l^{5}$ with the Inhaled Corticosteroids Questionnaire showed that $45 \%$ of patients reported moderate to severe side effects due to ICS when given in a dose $\geqslant 800 \mathrm{mcg}$ budesonide daily.

A study from Chambers et al. ${ }^{6}$ showed that $38 \%$ of patients who started ICS treatment subsequently stopped because of perceived side effects. However, side effects are seldom mentioned by patients, both in randomised controlled trials and in primary care consultations. Possibly this is because patients hesitate to talk about side effects because they are ashamed of discontinuing ICS treatment following such mild (but for them troublesome) side effects. Discontinuation of ICS is the most common cause of lack of asthma control in mild to moderate asthma. Therefore, the scientific community and interested clinicians should not only follow clinical guidelines but should also be alert to new drug developments.

Ciclesonide is an example of a new ICS that aims to reduce side effects by activation only in the lung, with low oral and high pulmonary deposition, high first pass effect in the liver and high protein binding in the bloodstream. ${ }^{1}$ Indeed, several clinical studies have confirmed these well documented claims. Agertoft and Pedersen ${ }^{7}$ showed that ciclesonide compared to fluticasone showed no lower leg growth rate reduction whereas fluticasone did. Derom et $a l^{8}{ }^{8}$ showed that cortisol suppression of ciclesonide was comparable with placebo whereas fluticasone led to marked cortisol suppression when both treatments were given at dosages leading to the same level of reduction in bronchial hyperresponsiveness. Finally, our group has shown that patients also perceive a difference in the number and intensity of side effects between ciclesonide and fluticasone in comparable dosages. ${ }^{9}$

The linked paper by Kuo-Chin et al. ${ }^{10}$ is an open-label, 12-week study comparing the effect of ciclesonide $(320 \mathrm{mcg})$ once daily with budesonide $(400 \mathrm{mcg})$ twice daily in a group of 150 patients with mild to moderate well-controlled asthma (asthma control test score $\geqslant 21$ ) who were stepped down from combination ICS/longacting $\beta_{2}$-agonist therapy. Drug adherence was higher in the ciclesonide group $(76.0 \%$ vs. $58.7 \%, P=0.03)$ than in the budesonide group. The results of this study show that patients had favourable results from ciclesonide (once daily) over budesonide (twice daily) and, more importantly, fewer patients discontinued treatment with ciclesonide than with budesonide. More patients in the ciclesonide group (70\%) were at least satisfied with their treatment, compared with $47.5 \%$ of patients in the budesonide group $(P=0.02)$. Unfortunately, the authors have not reported why the patients preferred ciclesonide. Was this because of the efficacy of the drug, the way of administering (once daily), or was the patient perceiving less side effects? One can only guess. However, the importance of the study lies in the withdrawal rate due to loss of asthma control-5\% in the ciclesonide group versus $27 \%$ in the budesonide group. This might be related to the far worse adherence in the latter group, different ICS particle sizes, or differences in drug deposition.

Therefore, clinicians should be aware that the dosage, inhaler type and the administration frequency, but also the choice of ICS drug, is important in modern clinical practice. The difference might not lie in efficacy per microgram but mostly in patients' appreciation of the balance between efficacy and potentially troublesome side effects. Ciclesonide therefore has several advantages over the other ICS, resulting in high efficacy and low adverse events-both local and systemic — which are relevant for clinical practice.

\section{COMPETING INTERESTS}

Tvd Molen recieved research funding from Nycomed, previous manufacturer of ciclesonide for the development of the Inhaled Corticosteroid Questionnaire. JWHK declares no competing interest.

Thys van der Molen ${ }^{1}$ and Janwillem WH Kocks ${ }^{1}$

${ }^{1}$ Department of General Practice, University of Groningen, University Medical Center Groningen, GRIAC Research Institute Groningen,

Groningen, The Netherlands

Correspondence: $T$ van der Molen (t.van.der.molen@umcg.nl) 


\section{REFERENCES}

1 Global Initiative for Asthma (GINA) 2012. Global Strategy for Asthma Management and Prevention. http://www.ginasthma.org, last accessed 13 May 2014.

2 Cazzola M, Segreti A, Bettoncelli G, Calzetta L, Cricelli C, Pasqua F et al. Change in asthma and COPD prescribing by Italian general practitioners between 2006 and 2008. Prim Care Respir J 2011; 20: 291-298.

3 Ford ES, Mannino DM, Giles WH, Wheaton AG, Liu Y, Croft JB. Prescription practices for chronic obstructive pulmonary disease: findings from the National Ambulatory Medical Care Survey 1999-2010. COPD 2014; 11 247-255.

4 Kraan J, Koeter GH, vd Mark TW, Sluiter HJ, de Vries K. Changes in bronchial hyperreactivity induced by 4 weeks of treatment with antiasthmatic drugs in patients with allergic asthma: a comparison between budesonide and terbutaline. J Allergy Clin Immunol 1985; 76: 628-636.

5 Foster JM, Aucott L, van der Werf RH, van der Meijden MJ, Schraa G, Postma DS et al. Higher patient perceived side effects related to higher daily doses of inhaled corticosteroids in the community: a cross-sectional analysis. Respir Med 2006; 100 $1318-1336$.

6 Chambers CV, Markson L, Diamond JJ, Lasch L, Berger M. Health beliefs and compliance with inhaled corticosteroids by asthmatic patients in primary care practices. Respir Med 1999; 93: 88-94.
7 Agertoft L, Pedersen S. Lower-leg growth rates in children with asthma during treatment with ciclesonide and fluticasone propionate. Pediatr Allergy Immunol 2010; 21(1 Pt 2): e199-e205.

8 Derom E, Van De Velde V, Marissens S, Engelstatter R, Vincken W, Pauwels R Effects of inhaled ciclesonide and fluticasone propionate on cortisol secretion and airway responsiveness to adenosine 5 'monophosphate in asthmatic patients. Pulm Pharmacol Ther 2005; 18: 328-336.

9 van der Molen T, Foster JM, Caeser M, Muller T, Postma DS. Difference between patient-reported side effects of ciclesonide versus fluticasone propionate. Respir Med 2010; 104: 1825-1833.

10 Chiu K-C, Chou Y-L, Hsu J-Y, Lin M-S, Lin C-H, Chou P-C et al. Comparison of the efficacy of ciclesonide with that of budesonide in mild to moderate asthma patients after step-down therapy. npj Primary Care Respiratory Medicine 2014; 24, Article number: 14010; doi:10.1038/npjpcrm.2014.10.

(i) This work is licensed under a Creative Commons Attributioncc) NonCommercial-NoDerivatives 4.0 International License. The images or other third party material in this article are included in the article's Creative Commons license, unless indicated otherwise in the credit line; if the material is not included under the Creative Commons license, users will need to obtain permission from the license holder to reproduce the material. To view a copy of this license, visit http:// creativecommons.org/licenses/by-nc-nd/4.0/ 